P. MAJ*\#, B. ADAMCZYK-CIESLAK*, M. SLESIK* , J. MIZERA*, T. PIEJA**,

J. SIENIAWSKI***, T. GANCARCZYK**, S. DUDEK**

\title{
THE PRECIPITATION PROCESSES AND MECHANICAL PROPERTIES OF AGED INCONEL 718 ALLOY AFTER ANNEALING
}

\begin{abstract}
Inconel 718 is a precipitation hardenable nickel-iron based superalloy. It has exceptionally high strength and ductility compared to other metallic materials. This is due to intense precipitation of the $\gamma$ ' and $\gamma$ " strengthening phases in the temperature range $650-850^{\circ} \mathrm{C}$. The main purpose of the authors was to analyze the aging process in Inconel 718 obtained in accordance with AMS 5596, and its effect on the mechanical properties. Tensile and hardness tests were used to evaluate the mechanical properties, in the initial aging process and after reheating, as a function of temperature and time respectively in the ranges $650^{\circ}-900^{\circ} \mathrm{C}$ and 5-480 min. In addition, to link the mechanical properties with the microstructure transmission microscopy observations were carried out in selected specimens. As a result, factors influencing the microstructure changes at various stages of strengthening were observed. The authors found that the $\gamma$ " phase nucleates mostly homogenously in the temperature range $650-750^{\circ} \mathrm{C}$, causing the greatest increase in strength. On the other hand, the $\gamma^{\prime}$ and $\delta$ phases are formed heterogeneously at $850^{\circ} \mathrm{C}$ or after longer annealing in $800^{\circ} \mathrm{C}$, which may weaken the material.
\end{abstract}

Keywords: Inconel 718, mechanical properties, precipitations, heat treatment

\section{Introduction}

Inconel 718 is a commonly-used superalloy, especially in the aerospace and aviation industry. It has superior mechanical properties, even at high temperature, and good corrosion resistance [1]. Its high temperature strength is mainly achieved by complex chemical composition (Table 1) and precipitation hardening. The primary strengthening phase has been identified as the $\gamma$ " phase, with a chemical composition of $\mathrm{Ni}_{3} \mathrm{Nb}$, and a body centered tetragonal $\mathrm{DO}_{22}$ unit cell [2]. The precipitates have the form of thin coherent disc-shaped particles that nucleate along strictly defined crystallographic orientations in relation to the matrix $(\gamma)$ : $(001) \gamma " \|\{001\} \gamma$ and [100] $\gamma " \|(100) \gamma$. The strengthening effect of the $\gamma$ " phase is caused by three main factors: the high coherence of precipitates to the matrix, their small size (tens of nanometers), and their twinning ability, distinguishing it in comparison to the $\gamma$ ' phase, which is also present in the material [3]. However, it should be noted that the precipitates can only twin below a critical size, after exceeding a critical value the mechanism of deformation changes to simple shearing of precipitates by pairs of dislocations [4]. The second phase responsible for strengthening in Inconel 718 is $\gamma^{\prime}$ [5]. It consists of $\mathrm{Ni}_{3}(\mathrm{Ti}, \mathrm{Al})$ round precipitates with a simple cubic unit cell. Another phase in Inconel 718 is $\delta$ (also called $\beta$ ), with a chemical composition identical to that of the $\gamma$ " $\left(\mathrm{Ni}_{3} \mathrm{Nb}\right)$ phase [6]. It has an orthorhombic unit cell that is noncoherent to the matrix. It nucleates mainly at the grain boundaries; this process may cause brittleness of the material. In addition, $\mathrm{TiC}$ and $\mathrm{NbC}$

TABLE 1

Chemical Composition of Inconel 718

\begin{tabular}{|c|c|c|c|c|c|c|c|c|c|c|c|c|}
\hline & $\mathbf{N i}$ & $\mathrm{Cr}$ & $\mathbf{F e}$ & $\mathbf{N b}$ & Mo & $\mathbf{T i}$ & Al & Co & Mn & C & Si & $\mathbf{P}$ \\
\hline & \multicolumn{12}{|c|}{ Chemical composition [wt. \%] } \\
\hline $\operatorname{Max}$ & 55.00 & 17.00 & \multirow{2}{*}{ rest } & 4.75 & 2.80 & 0.65 & 0.20 & 1.00 & 0.35 & 0.08 & 0.35 & 0.015 \\
\hline Min & 50.00 & 21.00 & & 5.50 & 3.30 & 1.15 & 0.80 & - & - & - & - & - \\
\hline
\end{tabular}

\footnotetext{
* WARSAW UNIVERSITY OF TECHNOLOGY, FACULTY OF MATERIALS SCIENCE AND ENGINEERING, 141 WOŁOSKA STR., 02-507 WARSAW, POLAND

** PRATT \& WHITNEY RZESZÓW S.A., HETMAŃSKA 120 35-078 RZESZOW, POLAND

*** RZESZÓW UNIVERSITY OF TECHNOLOGY, DEPARTMENT OF MATERIALS SCIENCE, 2 WINCENTEGO POLA STR.35-959 RZESZOW, POLAND

\# Corresponding author: piotr.maj@inmat.pw.edu.pl
} 
primary carbides are also present in the material, although their presence is kept low, because they hinder the creation of $\gamma$ " and $\gamma^{\prime}[7]$.

Both the $\gamma^{\prime}$ and $\gamma$ " phases nucleate in the temperature range of $650^{\circ} \mathrm{C}$ up to $900^{\circ} \mathrm{C}$ in a relatively short period of time; above this temperature the dissolution of precipitates occurs in the material [8]. Extended exposure (over $1000 \mathrm{~h}$ ) reduces the needed temperature for $\gamma$ " nucleation to $550^{\circ} \mathrm{C}$ [9]. The order of their precipitation is a matter of debate, although there are some evidence that $\gamma$ " is more stable and occurs independently of $\gamma^{\prime}[10]$. Furthermore $\gamma^{\prime \prime}$ nucleation is dependent upon matrix defects: excess vacancy concentration dislocation and even stacking faults [11]. On the other hand, Cozar and Pineau [12] discovered that the alloy is very sensitive to chemical composition (especially the ratio of $\mathrm{Nb}, \mathrm{Ti}$, and $\mathrm{Al}$ ), when they assessed the kinetics of precipitation. A minor decrease in the niobium and a slightly elevated content of $\mathrm{Al}$ and $\mathrm{Ti}$ may lead to direct nucleation of $\gamma^{\prime}$, instead of $\gamma$ '. This again can cause a significant decrease in strength, especially at elevated temperature. The strong influence of $\gamma$ " is attributed to coherency strengthening [13] and an increase of strength in the temperature range 700$800^{\circ} \mathrm{C}[14]$.

The next phase considered by the authors is $\delta$. It is formed from $\gamma$ " twins, and also directly from the $\gamma$ matrix, in the temperature range $900-950^{\circ} \mathrm{C}$. As a result of its growth, depletion/ reduction of $\gamma$ " is observed in the near vicinity of $\delta$. This leads to heterogeneous weakening of the material, and the reduction of its ductility and maximum elongation during tensile tests [15]. There is also evidence that strain is an important factor enhancing the nucleation of the $\delta$ phase [16]. This is an important issue when planning hot forming of Inconel 718, since it is one of the reasons for hot cracking [17]. Beside the negative effects, $\delta$ hinders grain growth which may be advantageous from the point of view of some applications [6].

Precipitate strengthening is dependent on many factors, among others: 1) the size of the precipitates, 2) change in the lattice parameters of the precipitates in relation to the matrix (disorientation), 3) the volume fraction of the precipitates, 4) the precipitates' distribution in the matrix, and 5) their shape [10].

It has been proven that the strengthening effect of the $\gamma^{\prime}$ phase rises with particle size, although after reaching a critical value the hardness decreases with the diameter of the precipitates [18]. Another important factor is the disorientation parameter $\delta$ that describes the percentage difference between the matrix parameter to the precipitates. It has been proven that its increase hampers the dislocation movement strengthening the material. Furthermore the mismatch parameter influences the shape of the precipitates [19]. Additionally, in the case of the $\gamma$ ", the tetragonality of the phase should be taken into account, where $\mathrm{c} \approx 2 \mathrm{a}$. Furthermore, with a change of temperature the disorientation parameter may also vary, due to thermal expansion. Ultimately it may have a value up to $1.25 \%$ compared to the matrix. Higher values lead to stress concentration around the precipitates, which hampers the dislocation movement and generation of stacking faults. On other hand, this hinders the nucleation from the matrix of those precipitates.

The aging process of Inconel 718 was the subject of interests in many research papers [4,20-23]. In most of them the authors focused on the mechanical properties or the microstructure in the range of $500-750^{\circ} \mathrm{C}[24,25]$. It has been proven that the aging process is very sensitive to many material parameters $[12,23,26]$. Especially at higher temperature the nucleation process differs greatly resulting in a diverse morphology of participates compared to the standard heat treatment. Furthermore the mechanical response can change depending on the varying microstructure stemming from the prior heat treatment. It is generally known that precipitates nucleation and growth are the main factors influencing the properties of Inconel 718 however it is unclear how a second heat treatment (reheating) will influence the strength of the material and what microstructure components are dominant in the individual stages. The authors of the current work want to address those issues. Therefore the tests were conducted in a wide range of time and temperature to describe the link between the mechanical and microstructural aspects of the aging process in Inconel 718. In general the aim of this study was to analyze the changes of mechanical properties from the point of view of the changes that have occurred in the microstructure of the material.

In the present research, the influence of precipitation hardening on the mechanical properties and microstructure of Inconel 718 has been studied. Additionally, the material was reheated after reaching the highest strength after aging. The aim of this was to examine the stability of the microstructure, and to observe the degradation of the material after continuous heat treatment. In the discussion, the authors also describe the various stages of the precipitation process, and its impact on the mechanical properties.

\section{Experimental}

The studied material was nickel-iron alloy Inconel 718 cold-rolled sheet heat-treated in accordance with AMS 5596. The microstructure had equiaxed grains with a diameter of $17.5 \mu \mathrm{m}$. In addition few annealing twins and carbide inclusions were observed in the microstructure (Fig. 1). The average grain size (grain diameter) was calculated by stereological methods [27].

The material was annealed in a standard air resistance furnace within a temperature range of $650-900^{\circ} \mathrm{C}$ for a fixed time, from $5 \mathrm{~min}$ to $480 \mathrm{~min}(8 \mathrm{~h})$. The following procedure was used. The furnace was preheated to the desired temperature, and then stabilized at the given conditions to avoid inertia of the heating system. After stabilization, the material was inserted into the heating chamber. Again, the thermodynamic conditions were stabilized for $2 \mathrm{~min}(1 \mathrm{~min}$ per $1 \mathrm{~mm}$ of crosssection). The samples were then kept at the given temperature for a predetermined time. Finally, the samples were pulled out from the furnace and water cooled at $22^{\circ} \mathrm{C}$. The samples were 


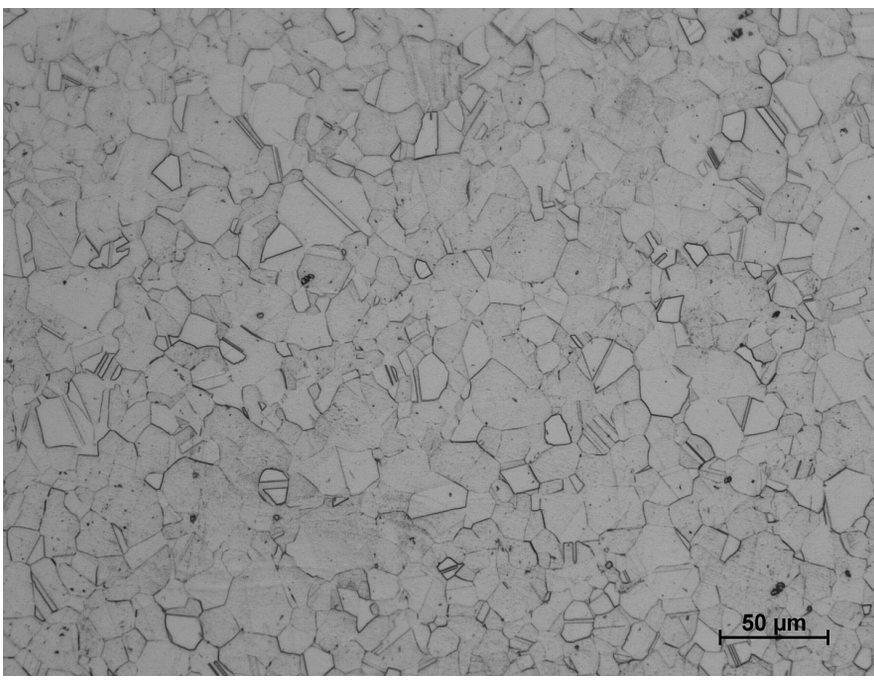

Fig. 1. Microstructure of Inconel 718 in the initial state

then studied by examining their mechanical properties, and also by transmission electron microscope. Additionally, the material with the highest hardness (annealed at $750^{\circ} \mathrm{C}$ for $480 \mathrm{~min}$ ) was reannealed under similar conditions as those used in the first stage of experiment, and then tested.

Tensile tests were carried out using a Zwick Z250 $250 \mathrm{kN}$ static machine, equipped with a precise mechanical extensometer for measuring the elongation. The method is specified in ISO 6892-2:2011. The samples were cut along the rolling direction and had a thickness of $2.1 \mathrm{~mm}$ and a gauge length of $35 \mathrm{~mm}$. The tests were performed at room temperature, with an initial constant strain rate of $10^{-3} \mathrm{~s}^{-1}$ until fracture, with a data retrieval frequency of $20 \mathrm{~Hz}$. To ensure adequate statistics, 3 tests were performed at each temperature. Supplementary hardness tests was carried out using the Vickers method, with a load of $20 \mathrm{kgf}$ and $15 \mathrm{~s}$ loading time.

Additional transmission electron microscopy (TEM) characterization was carried out in a similar manner, using a JEOL JEM 1200 EX 2 microscope, with an accelerating voltage of $120 \mathrm{kV}$. The samples $(100 \mu \mathrm{m}$ thick disks with a diameter of $3 \mathrm{~mm}$ ) were cut from heat treated sheets of Inconel 718 using wire electro-discharge machining (WEDM). The foils were next electropolished using A8 electrolyte provided by Struers.

TABLE 2

Summarized experiment parameters

\begin{tabular}{|c|c|c|c|c|}
\hline \hline & \multicolumn{2}{|c|}{ Initial state } & \multicolumn{2}{c|}{ After aging } \\
\hline & Time [min] & $\begin{array}{c}\text { Temperature } \\
{\left[{ }^{\circ} \mathbf{C}\right]}\end{array}$ & Time [min] & $\begin{array}{c}\text { Temperature } \\
{\left[{ }^{\circ} \mathbf{C}\right]}\end{array}$ \\
\hline $\begin{array}{c}\text { Tensile } \\
\text { tests }\end{array}$ & $\begin{array}{c}5,30,60, \\
180\end{array}$ & $650-900$ & - & - \\
\hline $\begin{array}{c}\text { Hardness } \\
\text { tests }\end{array}$ & $\begin{array}{c}5,30,60, \\
180,480\end{array}$ & $650-900$ & $\begin{array}{c}5,30,60, \\
180,480\end{array}$ & $650-900$ \\
\hline $\begin{array}{c}\text { TEM } \\
\text { tests* }\end{array}$ & $\begin{array}{c}5,60,180, \\
480\end{array}$ & $700-900$ & $\begin{array}{c}5,60,180, \\
480\end{array}$ & $750-900$ \\
\hline *Selected micrographs are shown in the article \\
\hline \multicolumn{5}{|c|}{} \\
\hline
\end{tabular}

\section{Results}

Tensile tests were conducted in the temperature range $650-900^{\circ} \mathrm{C}$, at which the effect of precipitates is the strongest $[28,29]$, to determine the impact of aging time and temperature on the mechanical properties of the investigated alloy. The reference sample had the highest elongation to fracture, and one of the lowest material strengths (Fig. 2). A general tendency can be observed that the maximum elongation decreases in the relation to the ultimate strength of the material for individual temperatures of annealing (Figs. 2,3). Furthermore, the changes were visible even from the shortest time of annealing ( 5 minutes), especially at $800^{\circ} \mathrm{C}$. The results indicate that the microstructure undergoes constant changes, dependent on the temperature and time. The changes are so rapid that they may occur at slower cooling rates after solution annealing, especially for large size elements. The strength of the material increased with annealing time, except for the temperature of $850^{\circ} \mathrm{C}$ (Fig. 3). The maximum ultimate tensile strength (UTS) was observed with the samples at 700 and $750^{\circ} \mathrm{C}$ (Fig. 4) for the longest time of annealing (480 min).

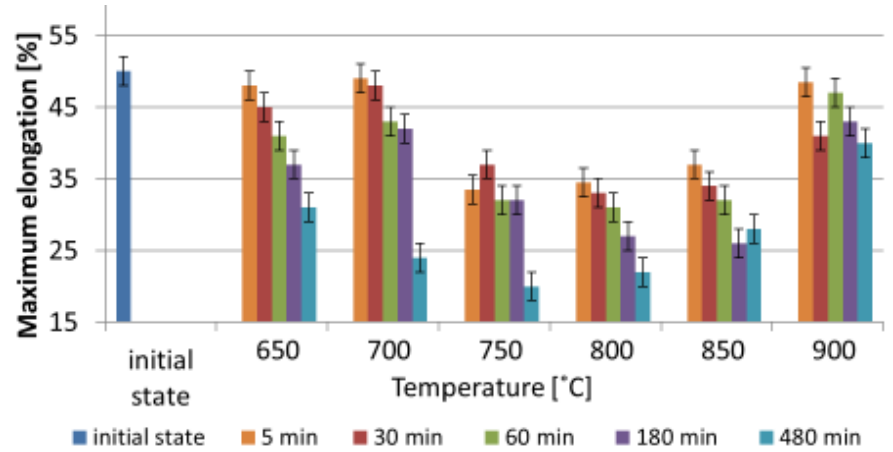

Fig. 2. Maximum elongation as a function of aging time and temperature

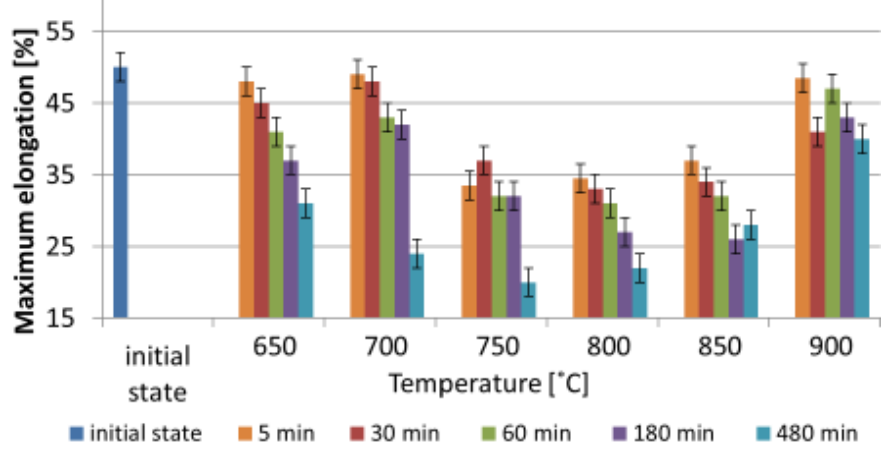

Fig. 3. UTS as a function of aging time and temperature

The next stage of the research concerned hardness measurements of the material after the initial and secondary annealing have been carried out (Fig. 5). The results obtained corresponded well with the tensile tests. The highest hardness was obtained for the aging parameters $750^{\circ} \mathrm{C}$ for $480 \mathrm{~min}$, while the lowest was for $900^{\circ} \mathrm{C}$ at $5 \mathrm{~min}$. The hardness of the material dropped gradually with time and the increase in temperature. Generally, longer time of annealing in the first stage of the experiment led 


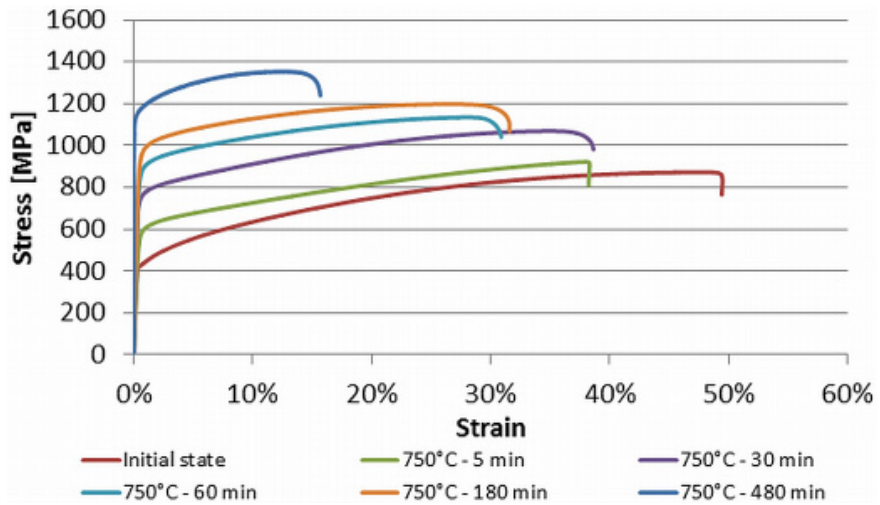

Fig. 4. Tensile tests Inconel 718 after heat treatment

to an increase in hardness; however, the rate of change varied, depending on the temperature. After reaching the highest hardness $\left(750-480^{\circ} \mathrm{C}\right)$ the material was again heat treated (Fig. $5 \mathrm{~b}$ ). The specimens were then tested using Vickers hardness. The main objective was to examine the mechanical properties of a two step-heat treatment material and describe the microstructure response at higher temperature. The strength of the material dropped gradually with time and the increase in temperature. The drop in strength can be explained by precipitation growth and the change in the deformation mechanism at the micro level from precipitate shearing to Orowan looping after exceeding critical size of particles [30]. Additionally after longer annealing time clusters of precipitates group along dislocations that will gradually grow and transform to $\delta$ phase weakening the material.

a)

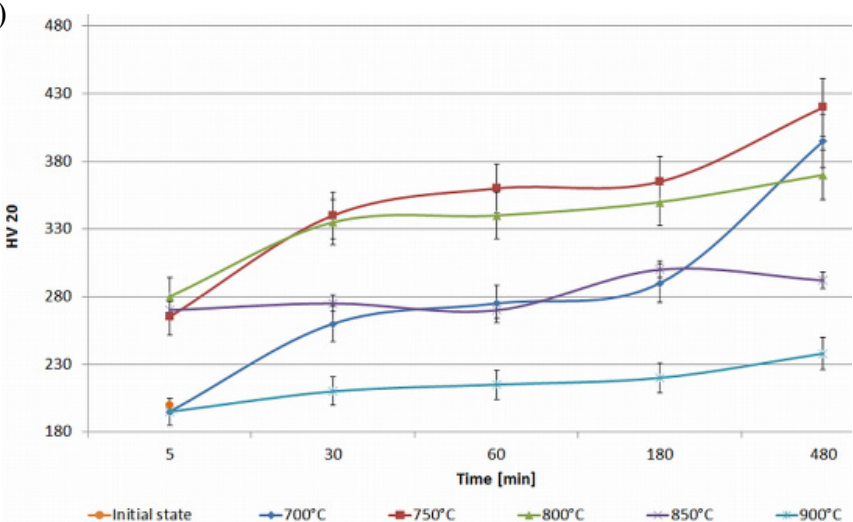

b)

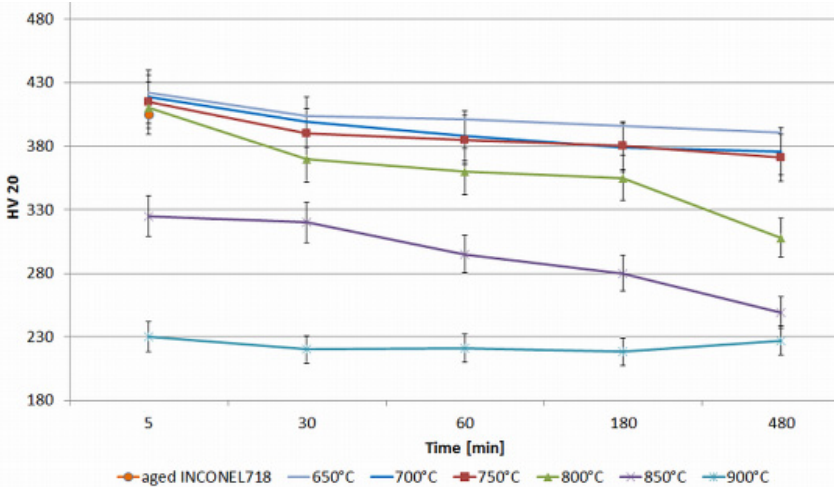

Fig. 5. The hardness of Inconel 718 as a function of time and temperature a) after first stage annealing (aging) and b) second (reheating)
On the basis of the obtained mechanical properties results for Inconel 718 the authors created a HV-UTS graph (Fig. 6). It can be seen that the data points are arranged along a line with a good fit $\left(R^{2}=0.8779\right)$. This agrees with the ASTM e140 standards however there is a large variation between the reference data (red line) and the current results obtained for Inconel 718 (black line). The greatest differences are visible for the underaged material while the high strength/hardness values obtained in this work are in a good agreement with the red line. According to Zhang et al [31] the observed divergence in this trend is caused by the difference in the deformation zone under the indenter. High ductile materials tend to have "sink in" indentation morphology which results in an overall decrease hardness in comparison to UTS.

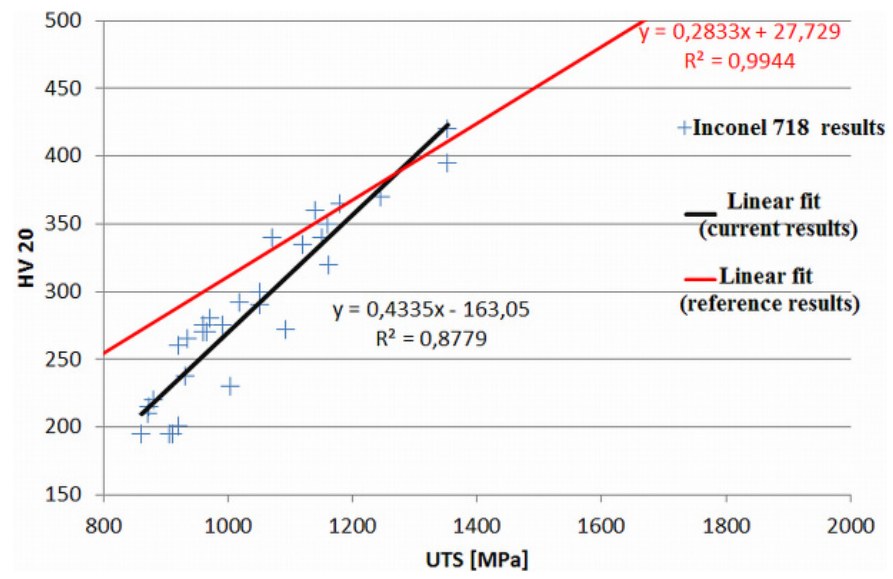

Fig. 6. UTS/HV graph for Inconel 718 after aging and reference data (ASTM e140)

Complementary research was carried out using TEM techniques. The tests were performed on selected samples for which the greatest changes of mechanical properties were observed. In the initial state the material had equiaxed grains, with a grain diameter of about $19 \pm 2 \mu \mathrm{m}$. A moderate concentration of dislocations gathering along slip lines could be seen in the whole specimen (Fig. 7a). Furthermore, some visible carbide precipitates were present along grain boundaries (Fig. 7b). For short times of annealing $(5 \mathrm{~min})$, the first changes of microstructure were seen at a temperature of $750^{\circ} \mathrm{C}$ (Fig. 7d). Small $\gamma$ " precipitates were visible at selected locations along which dislocation pileups could be seen. The result coincided with a slight increase of strength, and a decrease in elongation during mechanical testing. In the case of a temperature of $800^{\circ} \mathrm{C}$, the density of the precipitates was much higher although their occurrence was irregular. Their presence caused a significant increase in strength. Further increase of temperature led to precipitate coarsening. Additionally, preferential nucleation sites could be seen along some dislocations lines (Fig. 8a). Finally, at $900^{\circ} \mathrm{C}$ most $\gamma$ " precipitates disappeared (Fig. 10). There are only a few $\gamma$ ' precipitates still visible in the micrograph. They have the round shape that is typical for $\gamma$ ', and full coherence with the $\gamma$ matrix.

The next annealing time considered by the authors was 3h. At $700^{\circ} \mathrm{C}$ the specimen had barely visible $\gamma$ " precipitates (Fig. 7c). They were evenly distributed in the material, and had 

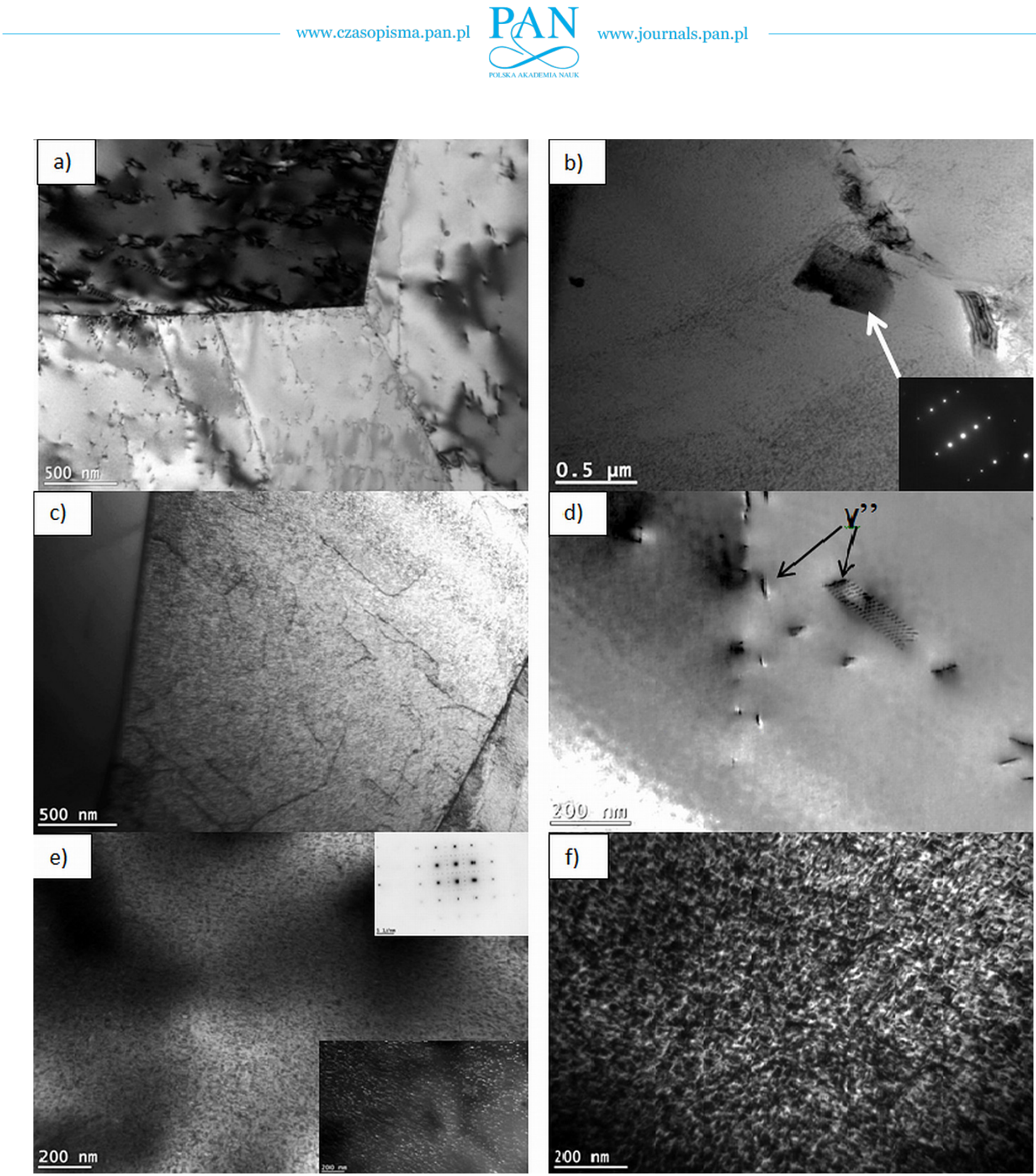

Fig. 7. The tested material a) in the initial state, b) carbides along the grain boundary, c) after $180 \mathrm{~min}$ at $\left.700^{\circ} \mathrm{C}, \mathrm{d}\right)$ after $5 \mathrm{~min}$ at $750^{\circ} \mathrm{C}$, e) $3 \mathrm{~h}$ at $\left.750^{\circ} \mathrm{C}, \mathrm{f}\right) 8 \mathrm{~h}$ at $750^{\circ} \mathrm{C}$

a size below $20 \mathrm{~nm}$. A further increase in annealing time and temperature led not only to the coalescence of precipitates, but also caused heterogeneity of nucleation that may weaken the strengthening effect (Fig. 8). The precipitates clustered along dislocations lines, segregating to favorable nucleation sites. This again can weaken their strengthening effect, resulting in a reduced strength. Longer annealing times are needed to observe similar inhomogeneity at lower temperatures. Furthermore, at a temperature of $800^{\circ} \mathrm{C}$, longer times of annealing led to the formation of ribbon-like clusters of precipitates. The effect was most evident when analyzing the microstructure of reheated material at $850^{\circ} \mathrm{C}$ (Fig. 8), where segments of precipitation could be seen along the dislocation clusters. This phenomenon is caused by directional coagulation, also called "rafting" [32]. It should be noted that the material was not subjected to stress although as can be seen in the initial state in (Fig. 7a.) had a medium concentrations of dislocations which may suggest local stresses that lead to formation of rafts (Fig. 8d).

\section{Discussion}

This article concerns the changes of microstructure of Inconel 718 after annealing and the resultant $\gamma$ ' phase's mechanical properties after the heat treatment. The main goal of the authors was the extension of the work done by Thomas et al. [8]. Mechanical tests were carried out to a much greater extent, supplemented by TEM results. It is commonly known that aging causes a significant increase in the strength of the material. This is mainly due to the beneficial effect of precipitates that nucleate in 

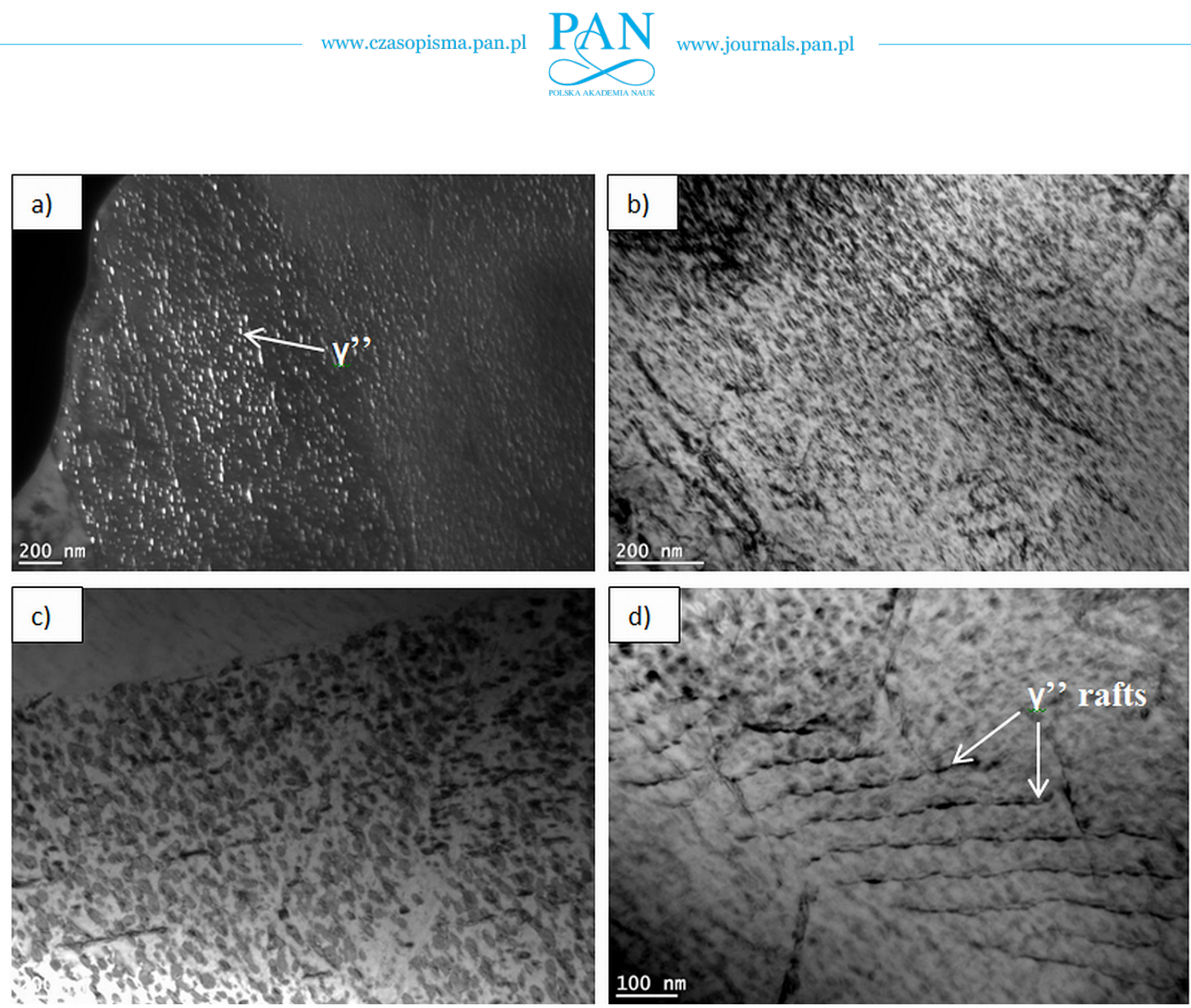

Fig. 8. Segregation of precipitates after reheating at $750^{\circ} \mathrm{C}$ a) $60 \mathrm{~min}$ (black field), b) $480 \mathrm{~min}$ at a temperature $\left.800^{\circ} \mathrm{C}, \mathrm{c}\right) 60 \mathrm{~min}$, d) $480 \mathrm{~min}$
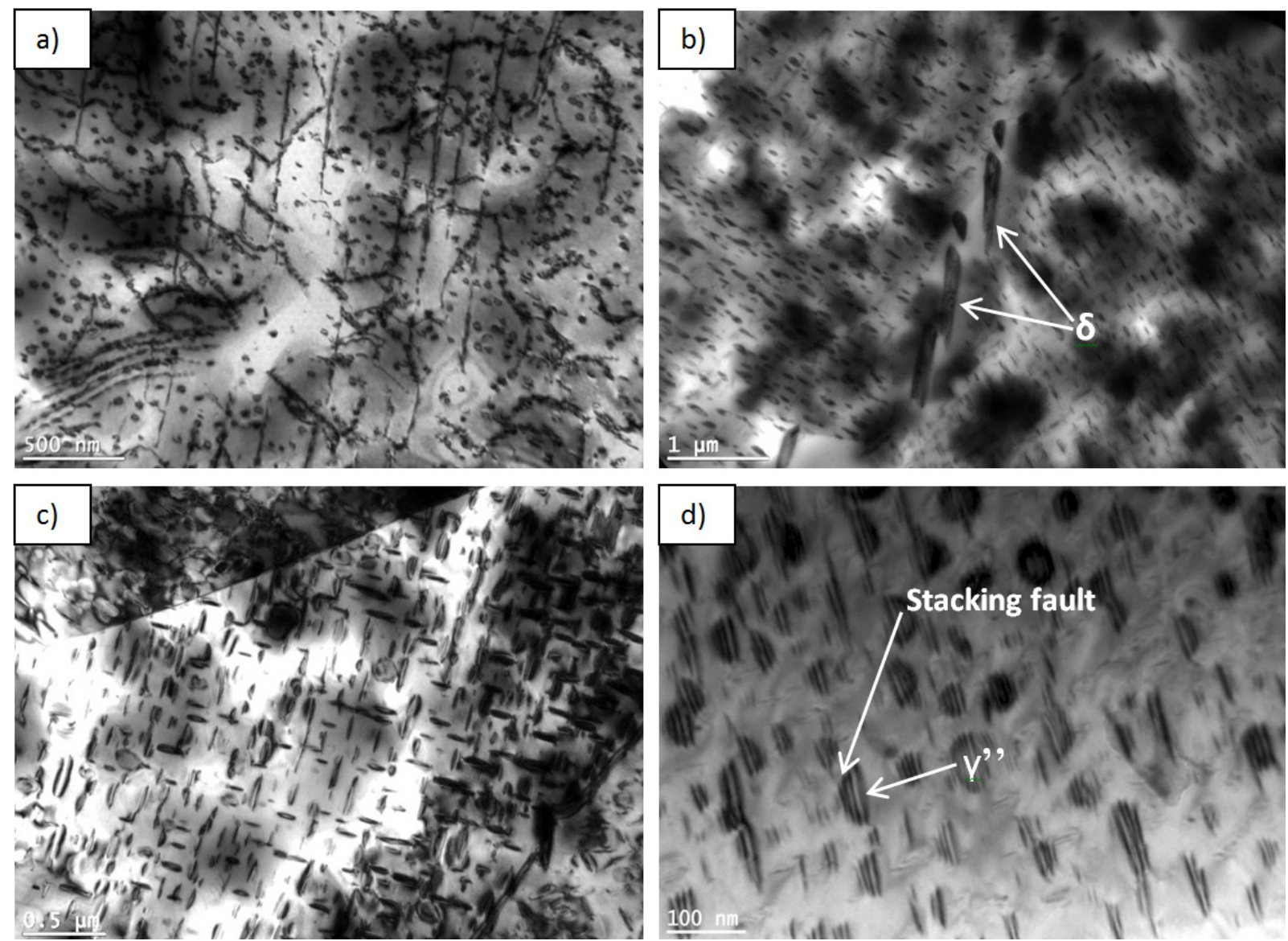

Fig. 9. Heterogeneous nucleation of precipitates at a temperature of $850^{\circ} \mathrm{C} \mathrm{a}$ ) $5 \mathrm{~min}$, b) $180 \mathrm{~min}$, and after aging and heating the material for $1 \mathrm{~h}$, c,d) 


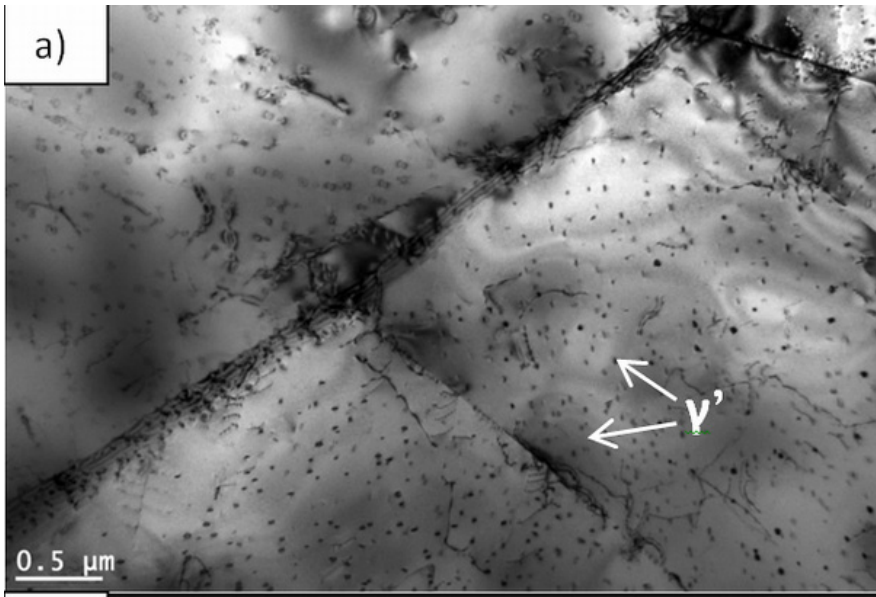

b)

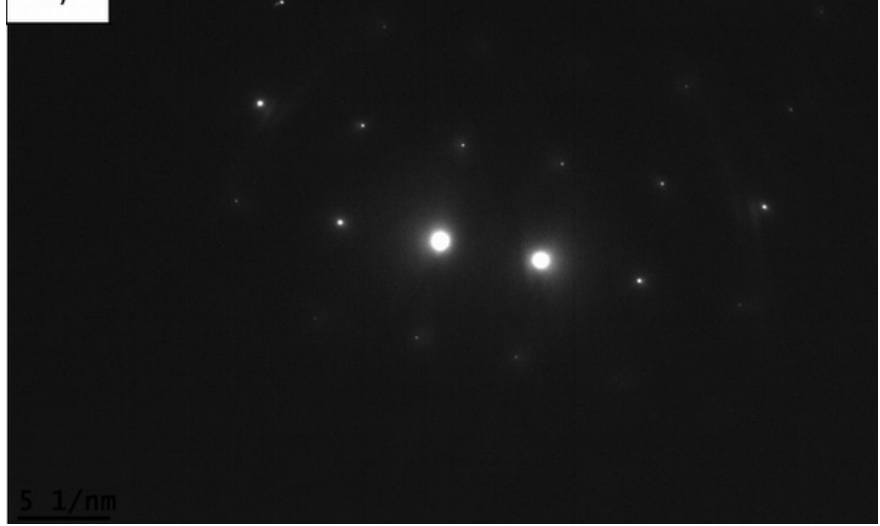

Fig. 10. The aged material after $5 \mathrm{~min}$ at $900^{\circ} \mathrm{C}$ a) bright-field microstructure and $b$ ) diffraction pattern from the precipitates

the material at a sufficiently high temperature. In case of Inconel 718 , the relevant temperature is in the range from $500-650^{\circ} \mathrm{C}$ (depending on the annealing time $[9,24]$ ) for the nucleation of the main strengthening phases, $\gamma$ ' and $\gamma$ ". They nucleate from the base solution of $\gamma$ by a replacive ordering of the matrix. The first clusters of $\gamma^{\prime}$ and $\gamma^{\prime \prime}$ are formed even after a short annealing time. Alam et al. [33] conducted a study concerning this issue by atom probe tomography. According to their results, the first clusters of $\mathrm{Nb}$ that form the $\gamma$ " phase can be seen just after 2 minutes. By comparison, $\mathrm{Al}$ and $\mathrm{Ti}$, which are responsible for the nucleation of $\gamma^{\prime}$, are only sprsely present in the whole tested volume. The process creates a high energy interface [10]. According to the current research at higher temperatures the process is more rapid, although there is a limit temperature of $900^{\circ} \mathrm{C}$ at which the precipitates dissolve (Fig. 10). For low temperatures, an incubation time of $30 \mathrm{~min}$ and $180 \mathrm{~min}$, for 650 and $700^{\circ} \mathrm{C}$ respectively, is necessary. However, from 750 up to $850^{\circ} \mathrm{C}$ the precipitation appears almost instantly (less than $5 \mathrm{~min}$ ) after heating the material (Fig. 7c and Fig. 8a). It is worth noting that in the current research for the temperature range of 650 up to $750^{\circ} \mathrm{C}$, the nucleation process is almost homogenous (Fig. 7c,e); this coincides with the observed high hardness (Fig. 4a). Evenly distributed precipitates emerge in the whole volume, creating a much finer microstructure in contrast to higher temperature treatment. In their work Cozar and Pineau [12] reported a compact morphology in the material after annealing at $700^{\circ} \mathrm{C}$ for $24 \mathrm{~h}$ which suggest ordering of both phases at longer annealing time. On the other hand, the current research proves that at a temperature of $850^{\circ} \mathrm{C}$ the precipitates cluster along dislocations which suggest heterogeneous nucleation and later growth. Furthermore, their large size causes stress around them and a large concentration of stacking faults (Fig. 9d), due to loss of coherence which was also observed by Sundararaman [10].

Comparing the mechanical properties of the material at lower temperatures, it can be seen that after the initial rise of hardness the further increase in the parameter is much lower (Fig. 5). On the basis of the current work it may be explained by a further increase of the $\gamma$ " volume fraction, although the precipitates at some point exceed the critical size, reducing their strengthening effect. Their further growth leads to a decrease of strength caused by the change in deformation mechanism from precipitate shearing to Orowan looping, and the creation of the $\delta$ phase, which accumulates mainly on the grain boundaries. According to this work a smooth transition between clusters of the $\gamma$ " phase to those of the $\delta$ phase causes a gradual deterioration in the mechanical properties [15]. Furthermore, Slama et al. [21] showed that the key parameter responsible for the hardness drop is the size of the particles. The tetragonal distortion is a secondary factor that changes nonlinearly with time and temperature, although it also increases with the particle size. According to [24], after exceeding $100 \mathrm{~nm}$ the $\gamma$ " precipitates lose their coherency. Finally, after reaching $900^{\circ} \mathrm{C}-5$ min of annealing only round fully coherent precipitates can be seen in the tested specimen (Fig. 10). This are most likely $\gamma^{\prime}$ particles although this contradicts with the phase transition temperature (PTT) for Inconel 718 proposed by Slama et al [34]. Furthermore it suggests that the $\gamma^{\prime}$ can exist independently of $\gamma^{\prime \prime}$ in certain thermodynamic conditions.

The second part of the experiment concerned the degradation of the mechanical properties after aging treatment. The material with the highest hardness, i.e. $750^{\circ} \mathrm{C} 8 \mathrm{~h}$ (Fig. 7f), was reheated under similar conditions as in the initial stage of the experiment. In all studied cases a decrease of hardness was observed, although up to $750^{\circ} \mathrm{C}$ the decreases were relatively small, caused by the clustering of $\gamma$ " precipitates. The coarsening effect is accompanied by alignment of the precipitates (Fig. 8a). The current results correspond to simulations carried out by Zhou et al [35]. Further increase in the temperature of annealing leads primarily to the growth of precipitates (Fig. 8c,d and Fig. 9), and later on to their loss of coherency. Additionally according to Wei et al., with increasing temperatures some fluctuation of element content can be seen, depending on the tested phase [36]. A short time (5 min) already leads to a drastic drop in hardness and decrease in elongation, caused by the formation of the $\delta$ phase (Fig. 9b). What is most noticeable is that the hardness is still higher than after the annealing of the initial state in similar conditions (i.e. $850^{\circ} \mathrm{C}-5 \mathrm{~min}$ ). This is caused most probably by the high homogeneity of the precipitates after aging. Lastly, after only a short annealing time at a temperature of $900^{\circ} \mathrm{C}$, a dissolution of $\gamma$ " precipitates occurs, leaving only $\gamma$ ' (Fig. 10). 
From the above description of the experiment, a more general conclusion can be drawn. Firstly, the main factor that determines the growth of $\gamma$ " precipitates is temperature. Even the shortest time at higher temperatures will lead to much coarser particles. Moreover, their growth is facilitated by microstructure defects (Fig. 9a). This again will lead to nucleation limited growth of $\gamma$ " at the cost of the small particles. Those clusters most probably will later evolve into the $\delta$ phase (Fig. 9b). On the other hand, the increase of the heating time leads only to the clustering of precipitates along dislocations and defects (Fig. 8) or next to other particles as was observed by Pineau and Cozar [12]. This again causes nonhomogeneous distribution of the strengthening phase $\gamma$ ", although to a much lower extent than overheating. Round $\gamma^{\prime}$ precipitates are more stable, withstanding temperatures up to $900^{\circ} \mathrm{C}$.

\section{Conclusions}

The mechanical properties of Inconel are largely dependent on the annealing procedure. Even the shortest time may have a significant impact on further processing due heterogeneous nucleation of precipitates. This again has a long-term effect on the microstructure and resulting mechanical properties.

An extended annealing time leads ultimately to the coarsening and segregation of the main strengthening phase $\gamma$ " reducing the overall mechanical properties; however, it should be noted that overheating may have a greater effect on the properties of the material since it leads to rapid growth of precipitates.

The decrease in hardness in the reheated specimens was gradual. This was caused by the reduction of precipitate strengthening effect. After exceeding a certain size value leads to coherency loss precipitation looping and finally the formation of $\delta$ phase.

At a temperature of $850^{\circ} \mathrm{C}$, rapid segregation of particles on dislocations is visible even after only $5 \mathrm{~min}$. This will have an impact on the segregation of the precipitates, and eventually on the formation of the $\delta$ phase in the early stages of the heat treatment.

\section{Acknowledgments}

Financial support of the National Center for Research and Development in the program INNOLOT CASELOT INNOLOT/I/9/NCBR/2013 is gratefully acknowledged.

\section{REFERENCES}

[1] Z.S. Yu, J.X. Zhang, Y. Yuan, R. C. Zhou, H.J. Zhang, H.Z. Wang, Mater. Sci. Eng. A 634, 55 (2015).

[2] S. Fukuyama, K. Yokogawa, J. Mater. Sci 10, 293 (1994).

[3] M. Sundararaman, P. Mukhopadhyay, S. Banerjee, Acta Metall. 36, 847 (1988)
[4] L. Xiao, D.L. Chen, M.C. Chaturvedi, Scr. Mater. 52, 603 (2005).

[5] N.S. Stoloff, C.T. Sims, W.C. Hagel, The Superalloys II (John Wiley \& Sons, New York, 1987).

[6] S. Azadian, L.-Y. Wei, R. Warren, Mater. Charact. 53, 7 (2004).

[7] M. Sundararaman P. Mukhopadhyay, High Temp. Mater. Process. 11, 351 (1993).

[8] A. Thomas, M. El-Wahabi, J.M. Cabrera, J.M. Prado, J. Mater. Process. Technol. 177, 469 (2006).

[9] J.W. Brooks, P.J. Bridges, Superalloys 1988 Symp, 33 (1988).

[10] M. Sundararaman, P. Mukhopadhyay, and S. Banerjee, Superalloys 718, 625, 706 Var. Deriv. 419 (1994).

[11] I. Kirman, D.H. Warrington, Metall. Trans. 1, 2667 (1970).

[12] D.A. Pineau, Metal. Mater. Trans. 4, (1973).

[13] J.M. Oblak, D.F. Paulonis, D.S. Duvall, Metall. Trans. 5, 143 (1974).

[14] A.K. Roy, A. Venkatesh, J. Alloys Compd. 496, 393 (2010).

[15] H.Y. Zhang, S.H. Zhang, M. Cheng, Z.X. Li, Mater. Charact. 61, 49 (2010).

[16] X. Wei, W. Zheng, Z. Song, T. Lei, Q. Yong, Q. Xie, J. Iron Steel Res. Int. 21, 375 (2014).

[17] J. Krawczyk, A. Łukaszek-Sołek, T. Śleboda, P. Bała, S. Bednarek, M. Wojtaszek, Arch. Metall. Mater. 57, 593 (2012).

[18] B. Geddes, H. Leon, X. Huang, in (2010), pp. 25-46.

[19] W.T. Loomis, J.W. Freeman, D.L. Sponseller, Metall. Trans. 3, 989 (1972).

[20] H. Jiahong, X.Y. Tang, S. Fukuyama, K. Yokogawa, 43, 4403 (1995).

[21] C. Slama, M. Abdellaoui, J. Alloys Compd. 306, 277 (2000).

[22] E. Chlebus, K. Gruber, B. Kuźnicka, J. Kurzac, T. Kurzynowski, Mater. Sci. Eng. A 639, 647 (2015).

[23] Y. Mei, Y. Liu, C. Liu, C. Li, L. Yu, Q. Guo, H. Li, J. Alloys Compd. 649, 949 (2015).

[24] C. Slama, C. Servant, G. Cizeron, J. Mater. Res. 12, 2298 (1997).

[25] D. Zhang, W. Niu, X. Cao, Z. Liu, Mater. Sci. Eng. A 644, 32 (2015).

[26] S.-H. Zhang, H.-Y. Zhang, M. Cheng, Mater. Sci. Eng. A 528, 6253 (2011).

[27] J. Michalski, T.O. Wejrzanowski, R. Pielaszek, K.A. Konopka, W. Lojkowski, K.J. Kurzydlowski, Mater. Sci. 23, 79 (2005).

[28] D. Keiser, H. Brown, Review of the Physical Metalurgy of Alloy 718 (AERO JET NUCLEAR COMPANY, 1976).

[29] M. Sundararaman, R. Kishore, P. Mukhopadhyay, Metall. Mater. Trans. A 25, 653 (1994).

[30] L.M. Camus, G. Engberg, High Temp. Mater. Process. 9, 27 (1990).

[31] P. Zhang, S.X. Li, Z.F. Zhang, Mater. Sci. Eng. A 529, 62 (2011).

[32] F.R.N. Nabarro, Metall. Mater. Trans. A 27, 513 (1996).

[33] T. Alam, M. Chaturvedi, S.P. Ringer, J. M. Cairney, Mater. Sci. Eng. A 527, 7770 (2010).

[34] C. Slama, G. Cizeron, J. Phys. III 7, 665 (1997).

[35] N. Zhou, D.C. Lv, H.L. Zhang, D. McAllister, F. Zhang, M.J. Mills, Y. Wang, Acta Mater. 65, 270 (2013).

[36] X. Wei, W. Zheng, Z. Song, T. Lei, Q. Yong, Q. Xie, J. Iron Steel Res. Int. 20, 88 (2013). 